\title{
RESEARCH
}

\section{Analysis of Admission and Program Variables as Predictors of the North American Pharmacist Licensure Examination}

\author{
Jaime Maerten-Rivera, PhD, ${ }^{\text {a }}$ Sharon K. Park, PharmD, Med, ${ }^{\mathrm{b}}$ Karen Sando, PharmD, ${ }^{\mathrm{c}}$ Nina Pavuluri, PhD, ${ }^{\mathrm{d}}$ \\ Jennifer Phillips, PharmD, ${ }^{\mathrm{e}}$ Lisa Lebovitz, JD, MS, ${ }^{\mathrm{f}}$ Yichen Zhao, BS ${ }^{\text {a }}$ \\ ${ }^{\text {a }}$ State University of New York at Buffalo, School of Pharmacy and Pharmaceutical Sciences, Buffalo, New York \\ ${ }^{\mathrm{b}}$ Notre Dame of Maryland University, School of Pharmacy, Baltimore, Maryland \\ ${ }^{\mathrm{c}}$ Nova Southeastern University, Fort Lauderdale, Florida \\ ${ }^{\mathrm{d}}$ Lake Erie College of Osteopathic Medicine, School of Pharmacy, Erie, Pennsylvania \\ ${ }^{\mathrm{e}}$ Midwestern University, College of Pharmacy, Chicago, Illinois \\ ${ }^{\mathrm{f}}$ University of Maryland, School of Pharmacy, Baltimore, Maryland
}

Corresponding Author: Lisa Lebovitz, University of Maryland, School of Pharmacy, 20 North Pine St., PH S303 21201, Baltimore, MD 21201. Tel: 410-706-3457. Email: 1lebovitz@rx.umaryland.edu

Submitted March 10, 2021; accepted August 2, 2021; ePublished August 2021

Objective. Understanding student characteristics and risk factors for North American Pharmacist Licensure Examination (NAPLEX) performance may help colleges and schools of pharmacy (C/SOPs) target limited resources. This study aimed to evaluate two sets of Doctor of Pharmacy (PharmD) student variables for their effect on NAPLEX performance.

Methods. Data were collected from five C/SOPs over three years (2016-18). Relationships between variables were first examined with bivariate correlations, followed by a series of multiple regressions using a structural equation modeling approach. Two sets of analyses were conducted using the outcome variable of NAPLEX scaled score; the first set examined variables at admission to the program while the second set examined performance variables during the PharmD program.

Results. Pharmacy Curriculum Outcomes Assessment (PCOA) area scores had the highest bivariate correlation with NAPLEX score; Area 4 and Area 2 had the strongest correlations. Pharmacy College Admission Test (PCAT) subtest scores were significant but had smaller correlations. Admissions variables of incoming science grade point average (GPA) and PCAT area scores were significant predictors of NAPLEX, but these were entered in separate models as they explained the same variance (each approximately 15\%). PharmD performance variables of PCOA area scores and GPA before Advanced Pharmacy Practice Experiences (pre-APPE GPA) were significant predictors and explained about 25\% of the variance in NAPLEX scores.

Conclusion. PCOA area scores and pre-APPE GPA were significant predictors of NAPLEX scores. Information in this study can be used by C/SOPs to efficiently target support services to students for enhanced NAPLEX performance. Keywords: NAPLEX, PCOA, PCAT, student characteristics, predictors

\section{INTRODUCTION}

The North American Pharmacist Licensure Examination (NAPLEX), administered by the National Association of Boards of Pharmacy (NABP), is a comprehensive assessment to determine the competency of knowledge, judgment, and skills expected of entry-level pharmacists. Doctor of Pharmacy (PharmD) graduates are required to pass the NAPLEX as part of the licensing process to practice pharmacy in the U.S. ${ }^{1}$ The six-hour examination consists of 250 questions that are delivered in a computerized, fixed form. At the time of this research, the NAPLEX competency statements outlined two major areas for the exam and the scores ranged from zero to 150 with the passing scaled score of 75 .

NABP publishes three years of recent NAPLEX first-time pass rates for colleges and schools of pharmacy (C/SOPs) on their website. In addition, schools are required by the Accreditation Council for Pharmacy Education (ACPE) to publicly disclose annual NAPLEX pass rates on their websites as an indicator of educational quality. ${ }^{2}$ NAPLEX pass rates may be used by potential applicants to compare C/SOPs, and a poor pass rate may negatively impact future student recruitment. There are also significant financial implications for individuals who fail the NAPLEX, including additional fees to retake the exam, and delay or loss of employment or residency. Therefore, C/SOPs devote supportive effort and resources to ensuring all students are well prepared to pass the NAPLEX. Identifying students who 
may need additional support upon admission, or those who may be at risk based on pharmacy school performance, is useful for schools to effectively target those resources appropriately.

Numerous publications in the past two decades have explored the relationship between student-specific variables and NAPLEX success. ${ }^{3-23}$ Variables evaluated for associations with NAPLEX performance can be organized into three major categories:1) student demographics (eg, age, race, ethnicity, prior degrees earned), 2) admission academic variables (eg, incoming grade point average [GPA], Pharmacy College Admission Test [PCAT] scores), and 3) pharmacy school GPA and Pharmacy Curriculum Outcomes Assessment (PCOA) scores. The current study conducted separate analyses for admission variables and performance variables during the PharmD program -while examining background variables in both - and found statistically significant predictors of NAPLEX scores from all three categories. Results from this study can help to inform when support services and resources are needed; for example, incoming students determined to be academically "at-risk" could be pre-enrolled in an early study skills course and could be supported with a robust tutoring program.

Given the importance of pass rates to both C/SOPs and graduates, it is critical for C/SOPs to understand the characteristics and risk factors of pharmacy students who are most likely to benefit from supportive services during matriculation. This study and others ${ }^{24}$ enable C/SOPs to target their scarce resources where they can make the greatest impact for student success. The purpose of this study was to evaluate two sets of comprehensive student variables for their impact on NAPLEX performance.

\section{METHODS}

Data were collected from five C/SOPs that participated in this research; no name or program identifier was collected. The C/SOPs in this study represented a mix of private and public universities with five four-year programs. One of the C/SOPs also had a three-year accelerated pathway. Data were submitted for students that took the NAPLEX in 2016, 2017, and 2018, and the PCOA in the pre-Advanced Pharmacy Practice Experiences (APPE) year. Each C/SOP submitted a de-identified data set with a line for each student with the following data: graduation year, gender, age, race/ethnicity (White, Asian, Black, Hispanic, Other), degree at entry in the PharmD (bachelor or higher or no degree), PCAT subtest scores (Biological Processes, Chemical Processes, Critical Reading, Quantitative Reasoning [if taken]), PCOA area scores (Basic Biomedical Sciences, Pharmaceutical Sciences, Social/Behavioral/Administrative Sciences, Clinical Sciences), PharmD GPA before APPE (pre-APPE GPA), and NAPLEX scaled score. C/SOPs obtained admissions data from PharmCAS and PCOA scores from NABP, and NAPLEX scores were obtained from NABP for students who authorized release through signature of the NABP Release of Information to Designated College of Pharmacy. These variables were selected based on previous literature and the first-attempt NAPLEX scaled scores were used as the outcome. The study was granted exemption from full review by the Nova Southeastern University institutional review board.

First, descriptive statistics were obtained for each variable in the data set. Next, relationships between variables were examined by calculating bivariate correlations. Pearson correlations were estimated for the continuous variables, and both Pearson correlation coefficient $(r)$ and the significance level were analyzed. In this study, Pearson correlation coefficients $(r)$ provided information on the magnitude of the effect or effect size of bivariate relationships. An $r$ less than .30 were considered small, between .30 and .50 moderate, and greater than .50 strong. ${ }^{25} \mathrm{~A} p$-value less than .05 was considered statistically significant. In addition, correlations above .80 were considered to indicate an issue of multicollinearity or independent variables in a model that are highly correlated and should not both be included in the model. $^{26}$

Next, a series of multiple regressions were conducted using a structural equation modeling approach and software (IBM SPSS Amos 26.0). This approach was used because it can account for missing data and uses information from maximum likelihood estimation to compute parameter estimates based on the data collected for each person (eg, if a student was missing PCAT scores, this still contributed to the estimates of the model). ${ }^{27}$ This is considered a more robust approach to handling missing data, especially compared with excluding cases due to missingness, which may introduce bias. This analysis provides estimates of the relationship between multiple predictor variables and the dependent or outcome variable. The inclusion of multiple predictor variables allows for the examination of the effect of each individual variable while statistically accounting for or "controlling" the effects of other variables.

Two sets of analyses were conducted using the outcome variable of NAPLEX scaled score. For each model, the standardized coefficient was presented $(\beta)$ and the significance level of the estimate, along with the unstandardized coefficient of the estimate (B). The $\beta$ can be used to compare the effects of predictor variables as it places them into a common metric. ${ }^{28,29}$ In addition, the $R^{2}$ for the model was presented which provides an estimate of the variance accounted for in the outcome variable (ie, NAPLEX scaled score) by the model. Further, the chi-square fit statistic for the model was 
reported, the degrees of freedom (df), and its probability value. This tests the null hypothesis that the predicted model and observed data are equal since predictions should ideally match the actual data as closely as possible. The root mean square error of approximation (RMSEA) is another measure of model fit, and generally, values less than 0.06 indicate that the model fit the data. ${ }^{30}$

Background variables (graduation year, gender, age, ethnicity, degree) were included in both sets of analyses to examine their impact and to reduce the variance in order to more accurately examine the effects of other predictor variables of interest. In the first set of analyses, variables that are traditionally collected during the admissions process were examined. In the first model (Model 1), the background variables and incoming science GPA were included as predictors. In the second model (Model 2), background variables and PCAT subtest scores were included as predictors. Both incoming science GPA and PCAT subtest scores were included in a model; however, the results suggested that the variables were counteracting each other because the amount of $\mathrm{R}^{2}$, which measures the amount of variance explained by the model, did not increase, and the coefficient for both variables were reduced. Further, the investigators recognized that many programs may require either incoming GPA or PCAT results at admission; thus, examining each in separate models seemed reasonable. The second set of analyses examined performance variables during the PharmD program and included PCOA scaled scores from each area and pre-APPE GPA, in addition to the background variables.

\section{RESULTS}

Between 2016 and 2018, a total of 2,910 PharmD students graduated from the five C/SOPs participating in data collection; 2,096 students from the three private institutions and 814 from the two public institutions. Not all student data were complete, and 2,123 students with identified first-time NAPLEX scores were included (73\% of the sample). Data were missing for students who did not authorize release of their NAPLEX scores through signature of the NABP Release of Information to Designated College of Pharmacy. In addition, one C/SOP did not provide data for one of the years, as it was unavailable. Descriptive information for the categorical variables collected and the reference group for each of the variables are listed in Table 1. Table 2 displays the descriptive information for the continuous variables. The overall mean NAPLEX scaled score was 93.7 ( $\mathrm{SD}=17.7)$. Table 3 presents the correlation analysis results. In general, the PCOA area scores had the highest correlation coefficient with the NAPLEX score ( $r$ ranged from .34 to .48 ). All PCOA area scores had statistically significant correlations greater than .30 suggesting moderate correlations with NAPLEX score; area 4 clinical sciences and area 2 pharmaceutical sciences had the strongest correlations with $r=.48(p<.01)$ and $r=.46(p<.01)$, respectively. The PCAT subtest scores had small, statistically significant correlations with the NAPLEX ( $r$ ranged from .15 to .21$)$ as did the incoming science GPA $(r=.21)$.

Table 4 presents the models related to admission variables. The data for both models did not fit well based on results of the Chi-square and RMSEA, suggesting that additional variables may be needed to improve the model. The amount of variance explained in the NAPLEX scores was similar for Model 1 (15\%) and Model 2 (14\%). Model 1 (Figure 1) examined the background variables and incoming science GPA as predictors. The predictors accounted for $15 \%$ of the total variance in NAPLEX scores. There were six statistically significant predictor variables: graduation year $2017(\mathrm{~b}=-$ $2.36, \beta=-0.06)$, age $22-25(b=-2.76, \beta=-0.08)$, age 26 plus $(b=-8.01, \beta=-0.19)$, ethnicity Asian $(b=-3.88, \beta=-0.10)$, ethnicity Black $(b=-10.04, \beta=-0.18)$, and incoming science GPA $(b=9.93, \beta=0.24)$. The coefficients suggest that students who graduated in 2017 scored on average 2.36 points lower on the NAPLEX compared to those graduated in 2016, students aged 22-25 scored on average 2.76 points lower on the NAPLEX compared to those 17-21, students aged 26 plus scored on average 8.01 points lower on the NAPLEX compared to those 17-21. Students who were Asian scored on average 3.88 points lower on the NAPLEX compared to Whites, students who were Black scored on average 10.04 points lower on the NAPLEX compared to Whites. Each one-point increase in incoming science GPA is associated with a 9.93 point increase on the NAPLEX. The Beta weights for the predictors suggest that graduation year 2017, age 22-25, and Asian ethnicity had small effects, while age 26 plus, ethnicity Black, and incoming science GPA all had moderate effects. The coefficients for Model 2 (Figure 2) were interpreted in a similar way and the coefficients of the background variables were similar to those in Model 1 (Figure 1). The PCAT biology, chemistry, reading, and verbal scores were all statistically significant predictors of NAPLEX scores, while the quantitative score was not. The effects of the PCAT reading $(\beta=0.05)$ and verbal $(\beta=0.05)$ were small, while the effects of biology $(\beta=0.13)$ and chemistry $(\beta=0.13)$ were moderate.

The results of the model examining PCOA area scores and pre-APPE GPA are presented in Table 5. The data for both models did not fit well based on results of the Chi-square and RMSEA, suggesting that additional variables may be needed to improve the model. The amount of variance explained in the NAPLEX scores in the model with both PCOA and Pre-APPE GPA was $25 \%$. The background variables performed similarly to the models examining admissions variables. The PCOA scores for area 1, area 2, and area 4 were all statistically significant predictors in both models with 
the effects of area $1(\beta=0.09)$ and area $2(\beta=0.14)$ having moderate effects and area 4 having a large effect $(\beta=0.25)$. When pre-APPE GPA was added to the model, it had a large effect $(\beta=0.35)$. Graphs of the model 2 is shown in Figure 3.

\section{DISCUSSION}

C/SOPs have long been interested in evaluating predictors of student success on the NAPLEX for a number of reasons including identifying applicants likely to be successful in the program, allocating resources for student support services, ensuring program accreditation, and enhancing school reputation. C/SOPs are required by ACPE to upload evidence of "relationship analysis of student variables, admission variables, and academic performance as part of the accreditation self-study report.". ${ }^{31}$ Additionally, most pharmacy programs have invested substantial resources into support services for program progression, and student NAPLEX preparation. In a 2016 survey of $91 \mathrm{C} / \mathrm{SOPs}$, nearly $80 \%$ reported that they provide some form of NAPLEX preparation, with the median annual spending on such programs reported to be $\$ 5,000$ to $\$ 9,999 .{ }^{32}$ As a result, factors have been evaluated for their potential predictive relationship to NAPLEX scores, including demographics and academics prior to and during the pharmacy program.

Student demographics and admission characteristics that have been positively associated with NAPLEX performance include younger age $\left(<25\right.$ years old) at admission, having no prior degrees, and higher PCAT scores. ${ }^{4,8,9}$ The current study's findings related to PCAT subtest scores and incoming science GPA were consistent with these studies. Variables of academic performance during the pharmacy program (GPA, unsatisfactory grades or failed courses, and remediation) have been evaluated in several studies, with the pharmacy program GPA frequently emerging as a significant predictor for the NAPLEX., ${ }^{4,12}$ Given that prepharmacy GPA may depend on the characteristics of the undergraduate institution attended and major or concentration the student pursued, the predictability of this variable for NAPLEX may not be useful. However, studies have shown no significant correlation between NAPLEX scores and prepharmacy institution or major. ${ }^{8,11}$

In the current study, pre-APPE GPA was found to add to the variance of explaining the NAPLEX success. This finding corroborates the results from Allen and Diaz ${ }^{14}$ in which the strongest positive correlation was found between cumulative didactic GPA and NAPLEX scores. Three other studies also demonstrated a similar result with cumulative GPA and NAPLEX success. ${ }^{4,8,12}$ Of note, both the pre-APPE GPA and final PharmD GPA have correlated positively to and were predictive of NAPLEX success, which emphasizes the importance of students' persistent performance in the program rather than their admissions profile.

The PCOA, also administered by NABP, is a three-hour standardized 225-question assessment that evaluates a student's foundational knowledge in four content domains (basic biomedical; pharmaceutical;

social/behavioral/administrative; and clinical sciences). ACPE requires that all C/SOPs deliver the PCOA to students near the end of the didactic curriculum. ${ }^{31}$ Five studies have evaluated the association between PCOA performance and the NAPLEX. ${ }^{5,13,15,16}$ Rudolph et al. ${ }^{5}$ was a multi-institutional study with a robust sample $(\mathrm{N}=14,634)$ that evaluated the relationship between PCOA and NAPLEX between 2012 and 2015. The PCOA was moderately and significantly correlated with NAPLEX score $(\mathrm{r}=.54)$. Only the overall score and the pharmaceutical and clinical sciences area scores of the PCOA were predictive of the NAPLEX score and accounted for approximately $30 \%$ of the variance in the NAPLEX score. However, this study did not include any other student factors, such as pharmacy school GPA, which emerged in other studies as a predictor of NAPLEX performance.

A meta-analysis including eight studies investigating correlations between P3 GPA, PCOA area scores, and the NAPLEX found a similar association between PCOA and NAPLEX performance, with PCOA area scores accounting for 32 to $44 \%$ of the variability in NAPLEX scores. ${ }^{17}$ NABP recently distributed a report to C/SOPs, Exploring the potential of a PCOA passing standard 2020, that brought together two data points of 49,510 individuals across three cohort years who have a record of both a PCOA score and a NAPLEX score, and found the PCOA is a strong predictor of performance on the NAPLEX. ${ }^{33}$ The current study's results confirmed previous studies regarding the positive correlation between PCOA area scores and NAPLEX success and is distinguishable by its broad sample and separate analyses. Among the six studies that have evaluated the association between PCOA performance and the NAPLEX, a majority of them were correlational analyses and were from a single institution. ${ }^{5,9,13,15,16,18}$

Many of the published studies examining factors associated with NAPLEX scores have limitations. These included small samples, typically fewer than 400 cases and often less than 200, and often draw a convenience sample from a single institution. ${ }^{4,5}$ Both of these factors can limit the generalizability of results. A number of studies evaluated only certain predictors (ie, demographics, PCOA), and some studies combined both admission variables and pharmacy program performance variables into the same model when typically, students are assessed at admission and later evaluated for risk of failure based on program performance. ${ }^{24}$ Combining these two sets of information into one model may reduce the impact of certain variables, because the predictor variables in the model are related and effects are canceled out. Even 
NABP's 2020 report comparing PCOA and NAPLEX scores recognized the limitations of their study with a statement that "Further analysis of the data is warranted to improve the accuracy of the predictions as well as identify critical determinants. Future areas of focus will examine differences at the college and school levels." ${ }^{33}$ The current study attempted to mitigate limitations by utilizing data from diverse institutions across multiple years, gathering a broad set of variables, and by separately analyzing data prior to and during pharmacy school. However, the study is also largely limited by the number of institutions and the student population included, the number of years reviewed - including 2016 when the new NAPLEX blueprint was in effect - and missing data such as PCAT scores.

\section{CONCLUSION}

This multi-institution study demonstrated that the admission variables explained $15 \%$ of the variance in NAPLEX scores while the performance variables during the PharmD program explained $25 \%$ of the variance in NAPLEX scores. The study used predictive modeling to gauge the predictability of each variable, notably each PCAT and PCOA content area and student-specific variables. C/SOPs may use these results to facilitate their strategies and resources to assist student's NAPLEX success.

\section{REFERENCES}

1. North American Boards of Pharmacy. North American Pharmacists Licensure Examination, Multistate Pharmacy Jurisprudence Examination 2020 Candidate Application Bulletin. Available at: https://nabp.pharmacy/wpcontent/uploads/2019/03/NAPLEX-MPJE-Bulletin July 2020.pdf. Accessed July 15, 2021.

2. American Council for Pharmacy Education. Policies and Procedures for ACPE Accreditation of Professional Degree Programs - January 2021. Available at: https://www.acpeaccredit.org/pdf/CS PoliciesAndProceduresJanuary2021.pdf. Accessed July 15, 2021.

3. Zarembski DG, Signatur DJ, Spunt AL, Wadelin JW. Comparative NAPLEX performance of graduates of US pharmacy programs accredited by ACPE prior to and since 1992. Am J Pharm Educ. 2005;69 (1-5):72-75.

4. Shaya FT, Lebovitz L, Gaitonde P, Schlesselman LS, Buring S. The well-rounded applicant (3 schools, 5 years of data): Admissions and other data as NAPLEX and MPJE performance determinants. Poster presented at the $116^{\text {th }}$ Annual Meeting of the American Association of College of Pharmacy. 2015. https://archive.hshsl.umaryland.edu/handle/10713/4628, accessed July 15, 2021.

5. Rudolph MJ, Gortney JS, Maerten-Rivera JL, Bray BS, Shah S, Hein BE, Coyle EA, Buring SM. A study of the relationship between the PCOA and NAPLEX using a multi-institutional sample. Am J Pharm Educ. 2019;83(2):6867. doi: 10.5688/ajpe6867.

6. Jimenez L, Ruiz N, Benavides S, Deb S, Caballero J, Parmar J. Comparison of NAPLEX pass rates for nonmodifiable determinants of pharmacy programs in the United States. Curr Pharm Teach Learn. 2019;11(11):11171122. doi.org/10.1016/j.cptl.2019.07.013

7. Williams JS, Spivey CA, Hagemann TM, Phelps SJ, Chisholm-Burns M. Impact of pharmacy school characteristics on NAPLEX first-time pass rates. Am J Pharm Educ. 2019;83(6):6875. doi: 10.5688/ajpe6875.

8. Shaya FT, Chirikov V, Lebovitz L, Layson-Wolf C, Morgan JA, Brammer JG, et al. Predictors of scores on the North American Pharmacists Licensure Examination (NAPLEX) differ by competency area. Poster presented at $115^{\text {th }}$ Annual Meeting of the American Association of Colleges of Pharmacy. 2014. Available https://archive.hshsl.umaryland.edu/handle/10713/4215, accessed July 15, 2021.

9. Shah S, Peng I, Seifert CF. A model to predict NAPLEX outcomes and identify students needing additional preparation. Curr Pharm Teach Learn. 2019;11(8):810-817. doi: 10.1016/j.cptl.2019.04.009

10. McCall KL, MacLaughlin EJ, Fike DS, Ruiz B. Preadmission predictors of PharmD graduates' performance on the NAPLEX. Am J Pharm Educ. 2007;71(1):5.

11. Shaya FT, Chirikov V, Lebovitz L, Layson-Wolf C, Morgan JA, Brammer JG et al. Admissions and other data as NAPLEX and MPJE performance determinants. Poster presentation, 2014. Available https://archive.hshsl.umaryland.edu/handle/10713/4216, accessed July 15, 2021.

12. Chisholm-Burns MA, Spivey CA, Byrd DC, McDonough SLK, Phelps SJ. Examining the association between the NAPLEX, Pre-NAPLEX, and pre- and post-admission factors. Am J Pharm Educ. 2017;81(5):86. doi: 10.5688/ajpe81586

13. Hein B, Messinger NJ, Penm J, Wigle PR, Buring SM. Correlation of the pharmacy curriculum outcomes assessment and selected pre-pharmacy and pharmacy performance variables. Am J Pharm Educ. 2019; 83(3):6579.

14. Allen RE, Diaz C. Use of Preadmission criteria and performance in the doctor of pharmacy program to predict success on the North American Pharmacists Licensure Examination. Am J Pharm Educ. 2013;77(9): Article 193. 
15. Naughton CA, Friesner DL. Correlation of P3 PCOA scores with future NAPLEX scores. Curr Pharm Teach Learn. Curr Pharm Teach Learn. 2014;6(6):877-883.

16. Garavalia LS, Prabhu S, Chung E, Robinson DC. An analysis of the use of pharmacy curriculum outcomes assessment within one professional program. Curr Pharm Teach Learn. 2017; 9(2):178-184.

17. Daugherty K, Malcom DR. Assessing the relationship between didactic performance and standardized examination scores in pharmacy students. Am J Pharm Ed. 2020;84(8): Article 847712.

18. Hutchinson DJ, Souza JM, Lenhard LM. Pharmacy curriculum outcomes assessment (PCOA) as a predictor of performance on NAPLEX. Poster presented at 116th Annual Meeting of the American Association of Colleges of Pharmacy. National Harbor, MD; 2015.

19. Madden MM, Etzler FM, Schweiger T, Bell HS. The impact of pharmacy students' remediation status on NAPLEX first-time pass rates. Am J Pharm Educ. 2012;76(10):191. doi: 10.5688/ajpe7610191.

20. Congdon HB, Morgan JA, Lebovitz L. Impact of time allocation practices on academic outcomes for students from a 2-campus pharmacy school. Am J Pharm Educ. 2014;78(10):179.

21. Welch AC, Karpen SC. Comparing student performance on the old vs new versions of the NAPLEX. Am J Pharm Educ. 2018;82(3):6408. doi: 10.5688/ajpe6408.

22. Ware KB. Relationships Between Myers-Briggs Type Indicators and NAPLEX performances. Am J Pharm Educ. 2019;83(1):6787. doi: 10.5688/ajpe6787.

23. Spivey CA, Chisholm-Burns MA, Johnson JL. Factors associated with academic progression and NAPLEX performance among student pharmacists. Am J Pharm Educ. 2020;84(2): 7561. Doi: 10.5688/ajpe7561.

24. Park SK, Phillips J, Pavuluri N. Systematic review of predictors of success for the North American Pharmacist Licensure Examination. Am J Pharm Educ. 2021;85(5): 8591. DOI: https://doi.org/10.5688/ajpe8591

25. Cohen J. Statistical power analysis for the behavioral sciences (2nd ed.). Hillsdale, NJ: Lawrence Erlbaum Associates; 1988.

26. Mason C, Perreault W. Collinearity, power, and interpretation of multiple regression analysis. Journal of Marketing Research. 1991;28(3): 268-280.

27. Kreft IG, de Leeuw J. Introducing Multilevel Modeling. London; SAGE Publications, Ltd; 1998. doi:10.4135/9781849209366

28. Chatterjee S, Simonoff J. Handbook of regression analysis. Hoboken, New Jersey: Wiley; 2013.

29. Keith, T. Multiple regression and beyond: an introduction to multiple regression and structural equation modeling (2nd ed.). New York; Routledge, Taylor \& Francis Group; 2015.

30. $\mathrm{Hu} \mathrm{L}$, Bentler PM. Cutoff criteria for fit indexes in covariance structure analysis: Conventional criteria versus new alternatives. Structural Equation Modeling;1999;6(1): 1-55.

31. American Council for Pharmacy Education. Accreditation Standards and Key Elements for the Professional Program in Pharmacy Leading to the Doctor of Pharmacy Degree (Standards 2016). Jan 2015. Available at https://www.acpeaccredit.org/pdf/Standards2016FINAL.pdf. Accessed July 15, 2021.

32. Lebovitz L, Shuford VP, DiVall MV, et al. Creating an arms race? Examining school costs and motivations for providing NAPLEX and PCOA preparation. Am J Pharm Ed. 2017. 81(7): 5909.

33. National Association of Boards of Pharmacy. North American Pharmacist Licensure Examination. Exploring the potential of a PCOA passing standard. 2020. (Lemrey "Al” Carter, NABP Executive Director/Secretary, Email Communication to Deans of Schools and Colleges of Pharmacy, October 16, 2020). 
Table 1. Descriptive Analysis of Categorical Variables ( $\mathrm{N}=2,123)$

\begin{tabular}{lc}
\hline Item & $\mathbf{n}(\boldsymbol{\%})$ \\
\hline Graduation Year & \\
$2016^{\mathrm{a}}$ & $620(29.2)$ \\
2017 & $688(32.4)$ \\
2018 & $815(38.4)$ \\
Gender & \\
Male $^{\mathrm{a}}$ & $757(35.7)$ \\
Female $^{\text {Missing }}$ & $1,363(64.2)$ \\
Age & $3(0.1)$ \\
17-21 & \\
$22-25$ & $726(34.2)$ \\
26 plus & $890(41.9)$ \\
Missing & $496(23.4)$ \\
Ethnicity & $11(0.5)$ \\
Asian & \\
Black & $626(29.5)$ \\
Hispanic & $236(11.1)$ \\
Other & \\
White & \\
Missing & $568(17.3)$ \\
Degree & $825(38.7)$ \\
Degree (bachelor or higher) & $1226(57.7)$ \\
No degree & $888(41.8)$ \\
Missing & $9(0.4)$ \\
\hline
\end{tabular}

a This group was coded as the references group for comparisons in subsequent statistical models; ethnicity had two groups as the reference as these groups were not significantly different. 
Table 2. Descriptive Information for Continuous Variables

\begin{tabular}{lcccc}
\hline Item & Possible & No. Valid & Min/Max & Mean (SD) \\
\hline Incoming science GPA & $0-4$ & 1,941 & $1.98 / 4.00$ & $3.28(0.42)$ \\
PCAT biology scaled score & $200-600$ & 1,732 & $360 / 502$ & $416.7(19.4)$ \\
PCAT chemistry scaled score & $200-600$ & 1,731 & $356 / 505$ & $417.2(20.9)$ \\
PCAT quantitative scaled score & $200-600$ & 1,732 & $359 / 490$ & $407.1(17.8)$ \\
PCAT reading scaled score & $200-600$ & 1,732 & $338 / 460$ & $394.9(20.0)$ \\
PCAT verbal scaled score & $200-600$ & 1,672 & $346 / 495$ & $401.6(19.6)$ \\
PCOA area 1 scaled score & $0-700$ & 1,705 & $66 / 700$ & $347.4(68.0)$ \\
PCOA area 2 scaled score & $0-700$ & 1,705 & $160 / 511$ & $340.7(55.8)$ \\
PCOA area 3 scaled score & $0-700$ & 1,704 & $65 / 669$ & $347.0(69.3)$ \\
PCOA area 4 scaled score & $0-700$ & 1,705 & $113 / 566$ & $339.3(61.8)$ \\
NAPLEX scaled score & $0-150$ & 2,123 & $27 / 135$ & $93.7(17.7)$ \\
\hline
\end{tabular}

GPA $=$ grade point average, PCAT $=$ Pharmacy College Admission Test, PCOA $=$ Pharmacy Curriculum Outcomes Assessment, NAPLEX $=$ North American Pharmacist Licensure Examination 


\begin{tabular}{|c|c|c|c|c|c|c|c|c|c|c|c|c|}
\hline & & 1 & 2 & 3 & 4 & 5 & 6 & 7 & 8 & 9 & 10 & 11 \\
\hline 1 & Incoming science GPA & 1.00 & & & & & & & & & & \\
\hline & PCAT biology scaled & & & & & & & & & & & \\
\hline 2 & $\begin{array}{l}\text { score } \\
\text { PCAT chemistry scaled }\end{array}$ & $.15^{* *}$ & 1.00 & & & & & & & & & \\
\hline 3 & score & $.21^{* *}$ & $.59^{* *}$ & 1.00 & & & & & & & & \\
\hline 4 & $\begin{array}{l}\text { PCAT quantitative } \\
\text { scaled score }\end{array}$ & $.13^{* *}$ & $.41^{* *}$ & $.57^{* *}$ & 1.00 & & & & & & & \\
\hline 5 & $\begin{array}{l}\text { PCAT reading scaled } \\
\text { score } \\
\text { PCAT verbal scaled }\end{array}$ & .02 & $.43^{* *}$ & $.26^{* *}$ & $.30^{* *}$ & 1.00 & & & & & & \\
\hline 6 & score & .03 & $.51^{* *}$ & $.34^{* *}$ & $.34^{* *}$ & $.70^{* * *}$ & 1.00 & & & & & \\
\hline 7 & $\begin{array}{l}\text { PCOA area } 1 \text { scaled } \\
\text { score } \\
\text { PCOA area } 2 \text { scaled }\end{array}$ & $.16^{* *}$ & $.35^{* *}$ & $.24^{* *}$ & $.14^{* *}$ & $.20^{* *}$ & $.24^{* *}$ & 1.00 & & & & \\
\hline 8 & $\begin{array}{l}\text { score } \\
\text { PCOA area } 3 \text { scaled }\end{array}$ & $.20^{* *}$ & $.36^{* *}$ & $.25^{* *}$ & $.20^{* *}$ & $.39^{* *}$ & $.40^{* *}$ & $.51^{* *}$ & 1.00 & & & \\
\hline 9 & score & $.10^{* *}$ & $.31^{* *}$ & $.20^{* *}$ & $.17^{* *}$ & $.49^{* *}$ & $.50^{* *}$ & $.39^{* *}$ & $.59^{* *}$ & 1.00 & & \\
\hline 10 & $\begin{array}{l}\text { PCOA area } 4 \text { scaled } \\
\text { score }\end{array}$ & $.20^{* *}$ & $.35^{* *}$ & $.25^{* *}$ & $.16^{* *}$ & $.41^{* *}$ & $.41^{* *}$ & $.45^{* *}$ & $.69^{* *}$ & $.59^{* *}$ & 1.00 & \\
\hline 11 & NAPLEX scaled score & $.21^{* *}$ & $.22^{* *}$ & $.21^{* *}$ & $.15^{* *}$ & $.21^{* *}$ & $.20^{* *}$ & $.34^{* *}$ & $.46^{* *}$ & $.34^{* *}$ & $.48^{* *}$ & 1.00 \\
\hline
\end{tabular}


Table 4. Results of Model Using NAPLEX Score as Dependent Variable and Background and Admission Variables as Predictors $(\mathrm{N}=2,123)$

\begin{tabular}{|c|c|c|c|c|}
\hline \multirow[b]{2}{*}{ Variables } & \multicolumn{2}{|c|}{ Model 1} & \multicolumn{2}{|c|}{ Model 2} \\
\hline & $\begin{array}{c}\text { Unstandardized } \\
\text { Coefficient } \\
\text { b (SE) }\end{array}$ & $\begin{array}{c}\text { Standardized Coefficient } \\
\beta \\
\end{array}$ & $\begin{array}{c}\text { Unstandardized } \\
\text { Coefficient } \\
\text { b (SE) }\end{array}$ & $\begin{array}{c}\text { Standardized } \\
\text { Coefficient } \\
\beta \\
\end{array}$ \\
\hline Constant & $67.04(3.05) * * *$ & & $-46.45(18.20)^{*}$ & \\
\hline Graduation Year 2017 & $-2.36(0.77)^{* *}$ & -0.06 & $-2.79(0.76) * * *$ & -0.08 \\
\hline Graduation Year 2018 & $0.79(0.74)$ & 0.02 & $0.53(0.73)$ & 0.02 \\
\hline Female & $-0.54(0.75)$ & -0.02 & $0.51(0.74)$ & 0.01 \\
\hline Age $22-25$ & $-2.76(0.73) * * *$ & -0.08 & $-2.95(0.72) * * *$ & -0.08 \\
\hline Age 26 plus & $-8.01(0.85)^{* * *}$ & -0.19 & $-7.12(0.84) * * *$ & -0.17 \\
\hline Ethnicity Asian & $-3.88(0.79) * * *$ & -0.10 & $-5.23(0.78) * * *$ & -0.14 \\
\hline Ethnicity Black & $-10.04(1.14)^{* * *}$ & -0.18 & $-8.84(1.12) * * *$ & -0.16 \\
\hline Ethnicity Hispanic & $-1.54(0.95)$ & -0.03 & $0.24(0.93)$ & 0.01 \\
\hline Degree (bachelor or higher) & $0.82(0.73)$ & 0.02 & $-3.12(0.72) * * *$ & -0.09 \\
\hline Incoming science GPA & $9.93(0.88)^{* * *}$ & 0.24 & & \\
\hline PCAT biology scaled score & -- & -- & $0.12(0.02)^{* * *}$ & 0.13 \\
\hline PCAT chemistry scaled score & -- & -- & $0.11(0.02)^{* * *}$ & 0.14 \\
\hline PCAT quantitative scaled score & -- & -- & $0.04(0.02)$ & 0.04 \\
\hline PCAT reading scaled score & -- & -- & $0.05(0.02)^{*}$ & 0.05 \\
\hline PCAT verbal scaled score & -- & -- & $0.04(0.02) *$ & 0.05 \\
\hline $\mathrm{R}^{2}$ & 0.15 & & 0.14 & \\
\hline Chi-Square & 2325.0 & $\mathrm{df}=45, p<.001$ & $5913.06, \mathrm{df}=$ & $91, p<.001$ \\
\hline RMSEA & & 0.16 & $0.1^{\prime}$ & \\
\hline
\end{tabular}

$* p \leq .05, * * p \leq .01, * * * p \leq .001$

Standard coefficients $(\beta)$ less than .05 are considered very small, between .05 and .10 small, between .10 and .25 are considered moderate, and greater than .25 are considered large. 
Table 5. Results of Model Using NAPLEX Score as Dependent Variable and Background, PCOA and GPA Variables as Predictors $(\mathrm{N}=2,123)$

\begin{tabular}{lcccc}
\hline & \multicolumn{2}{c}{ Model 1 } & \multicolumn{2}{c}{ Model 2 } \\
\hline & $\begin{array}{c}\text { Unstandardized } \\
\text { Coefficient } \\
\mathrm{b}(\mathrm{SE})\end{array}$ & $\begin{array}{c}\text { Standardized } \\
\text { Coefficient } \\
\beta\end{array}$ & $\begin{array}{c}\text { Unstandardized } \\
\text { Coefficient } \\
\mathrm{b}(\mathrm{SE})\end{array}$ & $\begin{array}{c}\text { Standardized } \\
\text { Coefficient } \\
\beta\end{array}$ \\
\hline Constant & $35.68(3.88)^{* * *}$ & & $-3.45(4.89)$ & \\
Graduation Year 2017 & $-1.93(0.69)^{* *}$ & -0.06 & $-1.89(0.65)^{* *}$ & -0.05 \\
Graduation Year 2018 & $1.70(0.66)^{*}$ & 0.05 & $2.14(0.63)^{* * *}$ & 0.07 \\
Female & $0.72(0.67)$ & 0.02 & $-0.21(0.64)$ & -0.01 \\
Age 22-25 & $-1.47(0.66)^{*}$ & -0.04 & $-0.94(0.62)$ & -0.03 \\
Age 26 plus & $-5.20(0.76)^{* * *}$ & -0.14 & $-4.35(0.72)^{* * *}$ & -0.12 \\
Ethnicity Asian & $-0.87(0.71)$ & -0.02 & $-1.45(0.67)$ & -0.04 \\
Ethnicity Black & $-5.77(1.03)^{* * *}$ & -0.11 & $-5.34(0.97)^{* * * *}$ & -0.11 \\
Ethnicity Hispanic & $0.17(0.85)$ & 0.01 & $-1.26(0.81)$ & -0.03 \\
Degree (bachelor or higher & $-0.86(0.66)$ & -0.03 & $-1.45(0.62)^{*}$ & -0.05 \\
PCOA area 1 scaled score & $0.04(0.01)^{* * *}$ & 0.15 & $0.02(0.01)^{* * *}$ & 0.09 \\
PCOA area 2 scaled score & $0.06(0.01)^{* * *}$ & 0.19 & $0.04(0.01)^{* * *}$ & 0.14 \\
PCOA area 3 scaled score & $0.01(0.01)$ & 0.01 & $-0.01(0.01)$ & -0.01 \\
PCOA area 4 scaled score & $0.08(0.01)^{* * *}$ & 0.32 & $0.06(0.01)^{* * *}$ & 0.25 \\
Pre-APPE Pharmacy GPA & & & $17.55(0.95)^{* * * *}$ & 0.35 \\
\hline $\mathrm{R}^{2}$ & 0.20 & & 0.25 & \\
Chi-Square & $5494.77, \mathrm{df}=78, p<.001$ & & $6051.20, \mathrm{df}=91, p<.001$ \\
RMSEA & 0.18 & & 0.18 & \\
\hline
\end{tabular}

$* p \leq .05, * * p \leq .01, * * * p \leq .001$

Standard coefficients ( $\beta$ ) less than .05 are considered very small, between .05 and .10 small, between .10 and .25 are considered moderate, and greater than .25 are considered large 
Figure 1. Graphs of Admission Variables as Predictors (Table 4, Model 1)

Graphs of categorical predictor variables unstandardized coefficients

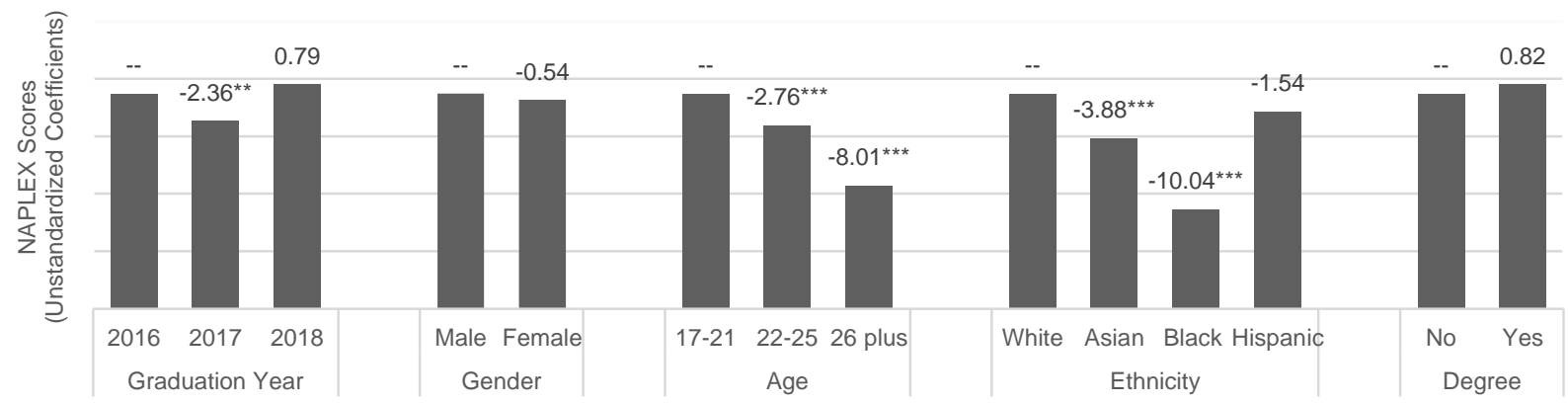

Graph of continuous predictor variable unstandardized coefficient

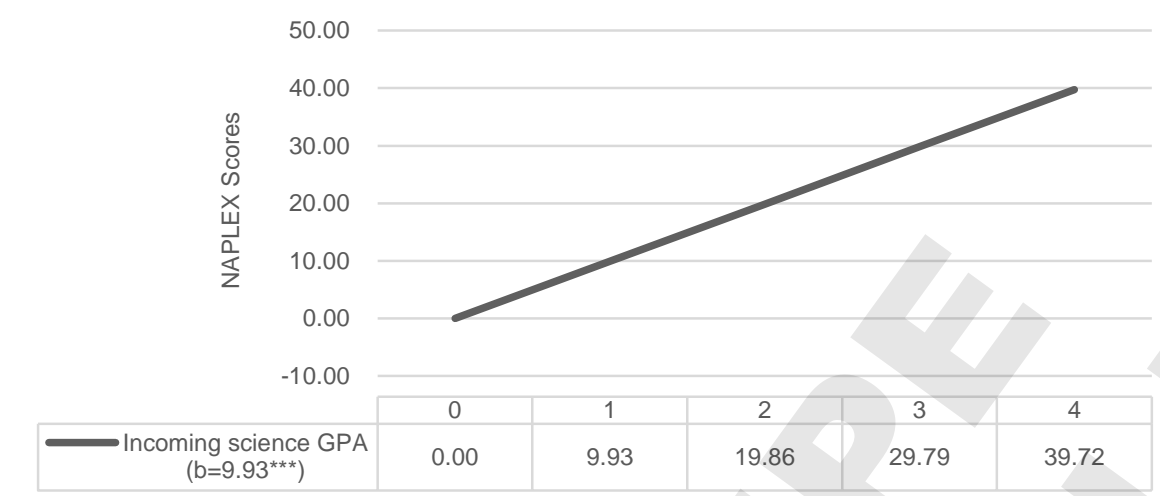

$* \mathrm{p} \leq .05, * * \mathrm{p} \leq .01, * * * \mathrm{p} \leq .001$ 
Figure 2. Graphs of Admission Variables as Predictors (Table 4, Model 2)

Graphs of categorical predictor variables unstandardized coefficients

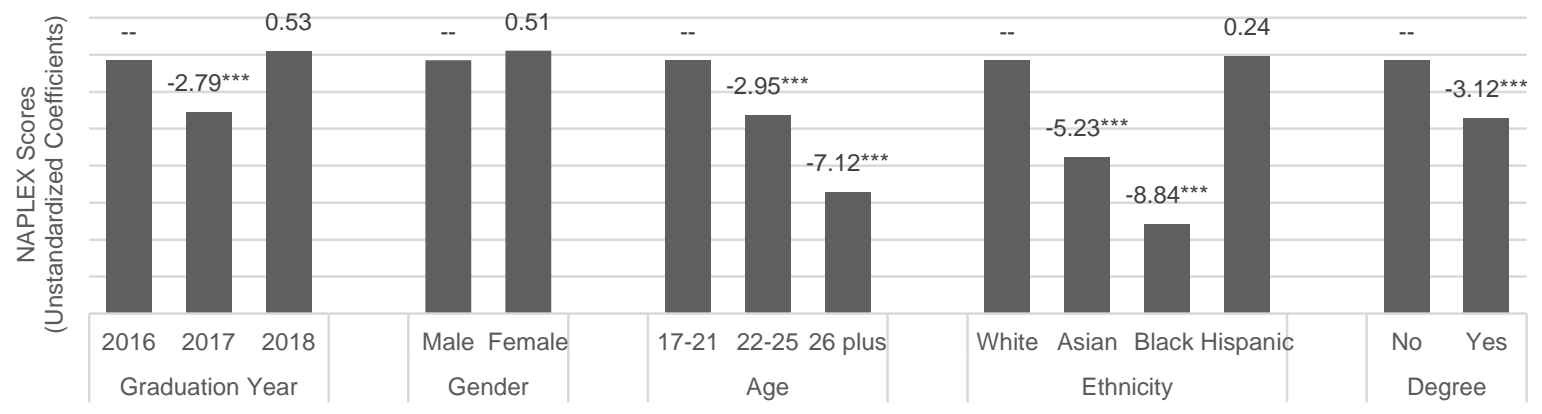

Graph of continuous predictor variables unstandardized coefficient

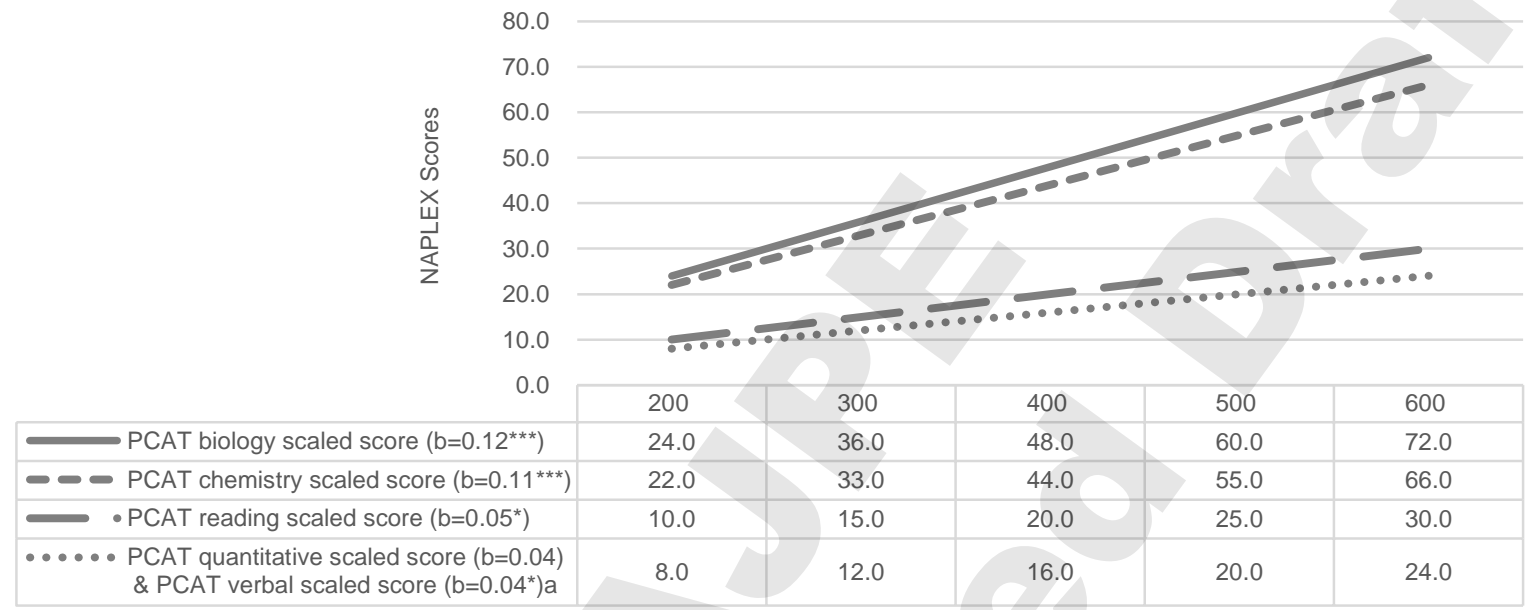

${ }^{a}$ PCAT quantitative scaled score and PCAT verbal scaled score had the equal unstandardized coefficient $(b=0.04)$. It was significant for verbal score but not for quantitative score.

$* \mathrm{p} \leq .05, * * \mathrm{p} \leq .01, * * * \mathrm{p} \leq .001$ 
Figure 3. Graphs of Background, PCOA, and GPA variables as Predictors (Table 5, Model 2)

Graphs of categorical predictor variables unstandardized coefficients

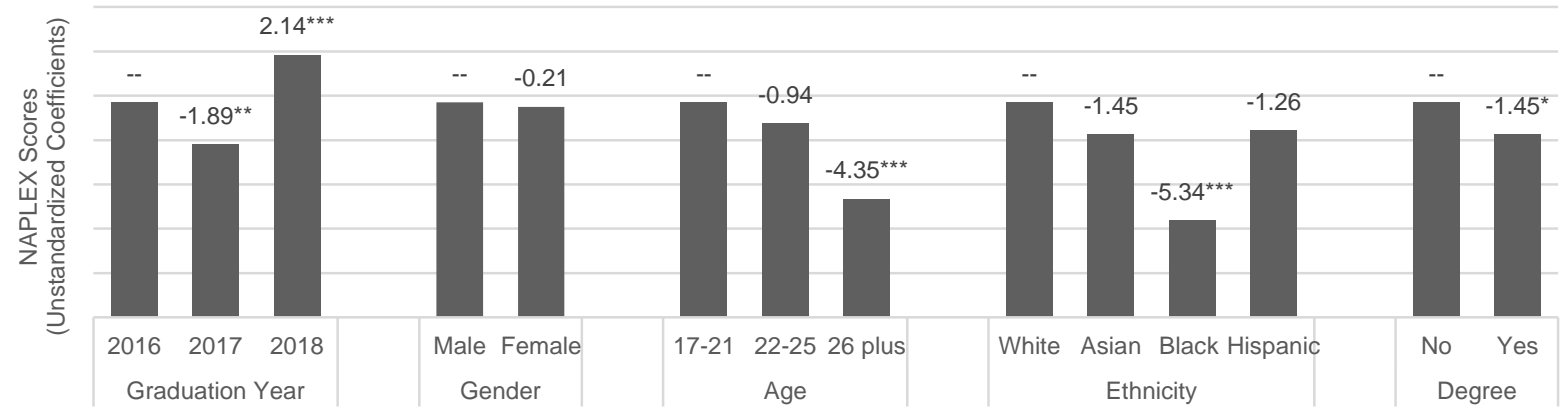

Graph of continuous predictor variables unstandardized coefficient
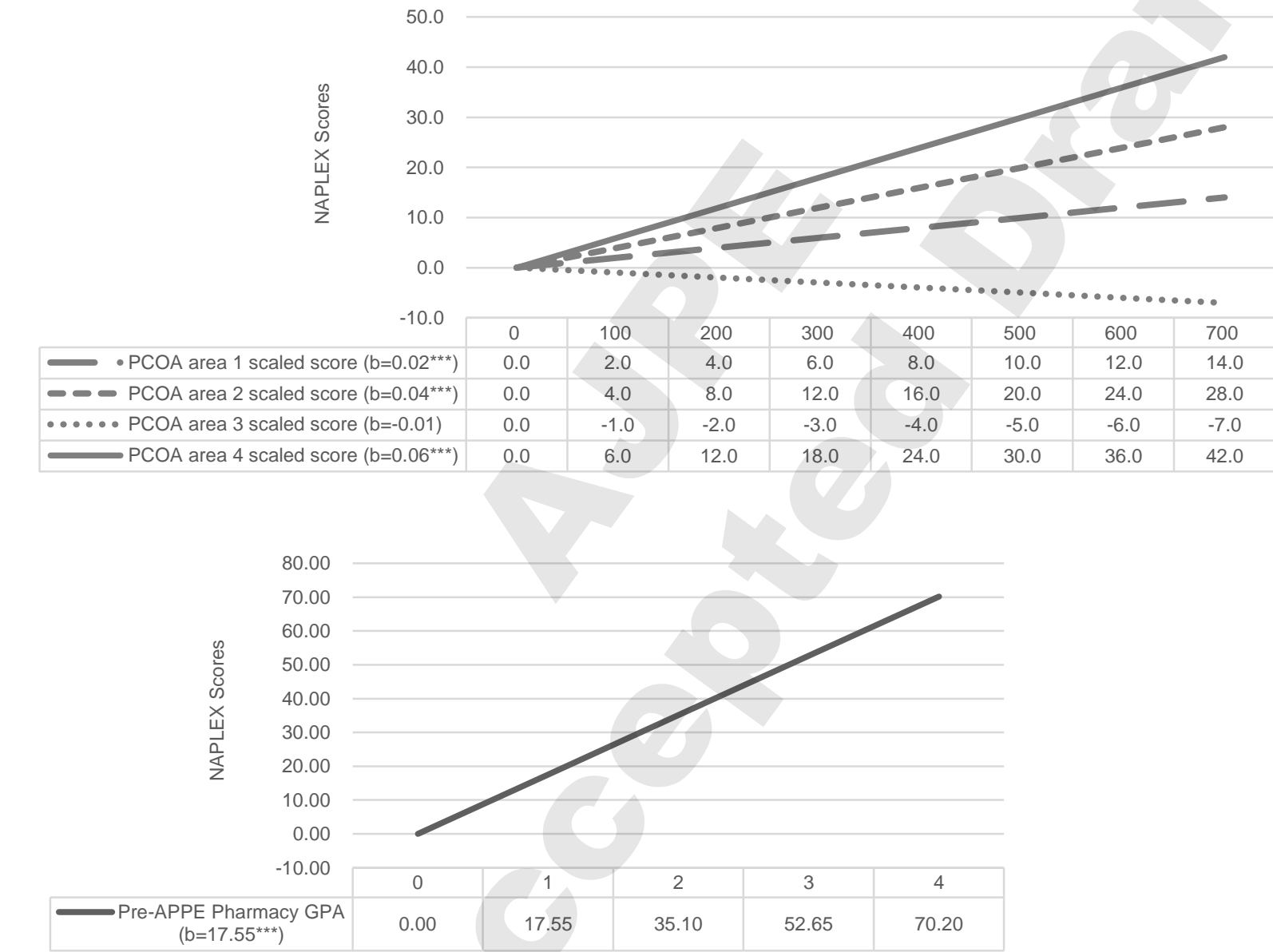

$* \mathrm{p} \leq .05, * * \mathrm{p} \leq .01, * * * \mathrm{p} \leq .001$ 